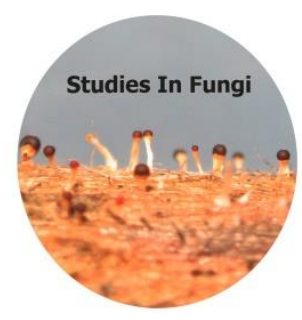

Studies in Fungi 2 (1): 210-217 (2017) www.studiesinfungi.org ISSN 2465-4973

\title{
Article
}

Doi 10.5943/sif/2/1/24

Copyright (C) Mushroom Research Foundation

\section{Neohelicosporium fusisporum sp. nov. (Tubeufiaceae) and a first record of a sexual morph within Neohelicosporium}

\section{Jayasiri SC ${ }^{1}$, Hyde KD ${ }^{1}$, Jones EBG ${ }^{2}$ and $\mathrm{Lu} \mathrm{YZ}^{3}$}

\author{
${ }^{1}$ Center of Excellence in Fungal Research, Mae Fah Luang University, Chiang Rai 57100, Thailand \\ ${ }^{2}$ Nantgaredig, 33B St. Edwards Road, Southsea, Hants. PO5 3DH, UK \\ ${ }^{3}$ Engineering and Research Center for Southwest Bio-Pharmaceutical Resources of National 8 Education Ministry of \\ China, Guizhou University, Guiyang, Guizhou Province 550025, P.R. China
}

Jayasiri SC, Hyde KD, Jones EBG, Lu YZ - 2017 Neohelicosporium fusisporum sp. nov. (Tubeufiaceae) and the first report of a sexual morph for the genus. Studies in Fungi 2(1), 210-217, Doi 10.5943/sif/2/1/24

\begin{abstract}
Both sexual and asexual morphs (holomorph) are known in several genera of Tubeufiaceae whereas in others, mainly the asexual or rarely the sexual morph is known. The genus Neohelicosporium is known only by its asexual morph, we have recently collected the sexual morph of the genus, which is characterized by fleshy, superficial ascomata, bitunicate asci, and hyaline to pale brown, fusiform ascospores. Analyses of combined ITS, LSU and tefl sequence data placed the taxon in Neohelicosporium. In this paper, we introduce the new taxon N. fusisporum based on both morphological characteristics and phylogenetic data.
\end{abstract}

Keywords - Bitunicate - fusiform - new species - phylogenetic data

\section{Introduction}

The family Tubeufiaceae is an interesting and important group of fungi with 23 genera, that includes saprobic, hyperparasitic or hypersaprobic species on ascomycetes and scale insects (Boonmee et al. 2011, 2014, Hyde et al. 2016, Brahamanage et al. 2017, Chaiwan et al. 2017, Lu et al. 2017a, b, c, d, Luo et al. 2017, Tanney \& Miller 2017). They are characterized by brightly pigmented, fleshy, superficial ascomata, bitunicate asci, and mostly hyaline to pale brownish, narrowly-elongate, obovoid or oblong septate ascospores (Boonmee et al. 2011, 2014). The asexual morphs of Tubeufiaceae have been well-studied and are mostly related to helicosporous taxa, such as Helicoma, Helicomyces and Helicosporium (Tsui et al. 2006, 2007, Hyde et al. 2011). However, helicosporous asexual morphs of Tubeufiaceae are now known to be present in several genera including Acanthohelicospora, Chlamydotubeufia, Helicangiospora, Helicoma, Helicomyces, Helicosporium, Neoacanthostigma, Neohelicomyces, Neohelicosporium and Tubeufia (Boonmee et al. 2014, Hyde et al. 2016, Brahamanage et al. 2017, Lu et al. 2017a, b, c, d, Luo et al. 2017).

In this study we introduce a sexual morph of a new species which was placed in Neohelicosporium according to the combined ITS, LSU and tefl phylogenetic data. The asexual morph of this new Neohelicosporium species was also found in culture. Lu et al. (2017d) introduced Neohelicosporium as an asexual genus in Tubeufiaceae and in our study, we record both the sexual and asexual morph of the new Neohelicosporium species. Most Tubeufiaceae species are commonly found on woody litter, however some species can also be found on leaf litters or even 
decaying cloths, and some are associated with other fungi or scale insects (Barr 1980, Rossman 1987, Kodsueb et al. 2006, Promputtha \& Miller 2010, Sánchez \& Bianchinotti 2010). In this paper, the new species Neohelicosporium fusisporum is introduced from Thailand which was found on a decaying fruit of a Malvaceae forest tree.

\section{Material and Methods}

\section{Sample collection and specimen examination}

The specimen was collected from Krabi, Thailand in 2015. Fruits collected were brought to the laboratory and observed using a Motic SMZ 168 Series microscope. Hand sections of fruiting structures were mounted in water for microscopic studies and photomicrography. The fungus was examined with a Nikon ECLIPSE 80i compound microscope and photographed with a Canon 450D digital camera connected to the microscope. Measurements were made with the Tarosoft (R) Image Frame Work program and images used for the figures were processed with Adobe Photoshop CS6 Extended version 10.0 software (Adobe Systems, USA). Isolations were made from single ascospores, following a modified method of Chomnunti et al. (2014).

The voucher specimen was deposited in the herbarium of Mae Fah Luang University (Herb. MFLU) and New Zealand Fungal \& Plant Disease Collection (PDD). The living cultures were deposited in the culture collection of Mae Fah Luang University (MFLUCC), Thailand with duplicates in BIOTEC Culture Collection (BCC), Bangkok, Thailand. Faces of fungi and IF numbers were obtained as in Jayasiri et al. (2015) and Index Fungorum (2017).

\section{DNA extraction, PCR amplification and sequencing}

Genomic DNA was extracted from the growing mycelium after 30 days on MEA at $18^{\circ} \mathrm{C}$ using the Biospin Fungus Genomic DNA Extraction Kit (BioFlux $\left.{ }^{\circledR}\right)$ following the manufacturer's protocol (Hangzhou, P.R. China). DNA amplifications were performed by Polymerase Chain Reaction (PCR). The partial large subunit nuclear rDNA (LSU) was amplified with primer pairs LROR and LR5 (Vilgalys \& Hester 1990). The internal transcribed spacer region of rDNA was amplified with primer pairs ITS1 and ITS4 (White et al. 1990). The translation elongation factor 1alpha gene (tefl) was amplified by using primers EF1-983F and EF1-2218R (Rehner \& Buckley 2005). The amplification procedure was carried in a $50 \mu \mathrm{l}$ reaction volume containing $2 \mu 1$ DNA, $25 \mu \mathrm{l}$ PCR mix, $19 \mu \mathrm{l}$ distilled water $2 \mu \mathrm{l}$ of each primer. The PCR reactions for amplification of ITS, LSU and tefl were performed under standard conditions (White et al. 1990). Purification and sequencing of PCR products were carried at Shanghai Sangon Biological Engineering Technology and Services Co. (China).

\section{Sequence alignment and phylogenetic analysis}

All sequences acquired from GenBank were used in Lu et al. (2017b, d). Multiple sequence $\begin{array}{llllll}\text { alignments were } & \text { generated with } & \text { MAFFT } & 6.864 \mathrm{~b}\end{array}$ (http://mafft.cbrc.jp/alignment/server/index.html) and further improved manually where necessary and datasets analyzed under different optimality criteria as outlined by Jeewon et al. (2013). All introns and exons were aligned individually. Ambiguously aligned regions with many leading or trailing gaps were excluded in alignments prior to tree building. Sequences generated from the ITS, LSU and tefl gene regions were carefully verified before further analyses. The final phylogenetic tree used to infer the taxonomic placement of our new taxon was generated based on DNA sequence analyses of a concatenated dataset of ITS, LSU and tefl. A maximum likelihood analysis was performed at CIPRES using RAxML v.7.2.8 as part of the "RAxMLHPC2 on TG" tool (Stamatakis et al. 2008, Miller et al. 2010). The general time reversible model (GTR) using proportion of invariable sites were applied with a discrete gamma distribution and four rate classes. The best scoring tree was selected with a final likelihood value of -28217.368593. Maximum likelihood bootstrap support (MLBS) equal or greater than 60\% are given near to each node (Fig. 1). 
The model of evolution was performed using jModeltest 2.1.7 (Guindon \& Gascuel 2003, Darriba et al. 2012). Posterior probabilities (PP) (Rannala \& Yang 1996, Zhaxybayeva \& Gogarten 2002) were determined by Markov Chain Monte Carlo sampling (MCMC) in MrBayes v. 3.0b4 (Huelsenbeck \& Ronquist 2001). Six simultaneous Markov chains were run for 1,000,000 generations and trees were sampled every $100^{\text {th }}$ generation. MCMC heated chain was set with a "temperature" value of 0.15 . All sampled topologies beneath the asymptote $(25 \%)$ were discarded as part of a burn-in procedure, the remaining trees were used for calculating posterior probabilities in the majority rule consensus tree. Bayesian Posterior Probabilities (BP) equal or greater than 0.90 is given near to each node (Fig. 1). Phylogenetic trees were drawn using FigTree v. 1.4 (Rambaut $\&$ Drummond 2008). The sequences of novel species are deposited in GenBank.

\section{Results}

\section{Phylogenetic analyses}

Multiple genes (ITS, LSU and tefl) were used for the phylogenetic analyses. The topologies of the obtained trees for each gene were compared manually, to verify that the overall tree topology of the individual datasets was congruent with the tree obtained from the combined alignment. The Bayesian analyses showed similar tree topologies and were congruent to those obtained in the ML analysis. The combined gene analysis of ITS, LSU and teflsequence data representing the genera of family Tubeufiaceae is shown in Fig. 1, which included 62 strains, representing 42 species and consisted of 3677 characters. Botryosphaeria dothidea (CBS 115476) is the outgroup taxon. The Bayesian analysis resulted in 7500 trees after 1,000,000 generations. The first 2500 trees, representing the burn-in phase of the analyses were discarded, while the remaining tree was used for calculating posterior probabilities in the majority rule consensus tree and is shown in Fig. 1. A best scoring RAxML tree resulted with the value of likelihood: -28217.368593 Phylogenetic trees obtained from ML and Bayesian analysis yielded trees with similar overall topology at the species level and in agreement with previous studies based on maximum likelihood and Bayesian analysis (Lu et al. 2017c, d). The new strain of Neohelicosporium species forms a sister clade to other Neohelicosporium spp. with moderate statistical support in maximum likelihood and high statistical support in Bayesian analyses (64\% MLBS, 0.94 BPP). Therefore, a new species is introduced to accommodate this taxon in the genus Neohelicosporium (N. fusisporum).

\section{Taxonomy}

Neohelicosporium fusisporum Jayasiri \& K.D. Hyde, sp. nov.

Figs $2-3$

Index fungorum number: IF553908; Facesoffungi number: FoF03785

Holotype - MFLU 16-0950

Etymology - "fusisporum" refers to the fusiform ascospores

Saprobic on the decaying fruit of Malvaceae sp. Sexual morph: Ascomata 340-400 $\mu \mathrm{m}$ high $\times 235-$ $290 \mu \mathrm{m}$ diam. $(\bar{x}=380 \times 255 \mu \mathrm{m})$, superficial, solitary, scattered, subglobose, ellipsoidal-ovate, with few hyphae developing from ascomatal base on substrate, pale brown to dark brown, velvety, ostiolate. Peridium 25-30 $\mu \mathrm{m}$ wide, comprising 3-4 layers, composed of cells of textura angularis, with inner cells brown and outer cells dark brown. Hamathecium comprising 1-2 $\mu \mathrm{m}$ wide, numerous, filiform, pseudoparaphyses. Asci 130-165 ×9-12 $\mu \mathrm{m}(\bar{x}=148 \times 11 \mu \mathrm{m}, \mathrm{n}=20)$, 8spored, bitunicate, cylindrical, apically thickened and rounded, with a pedicel. Ascospores $43-65 \times$ 1.6-4.6 $\mu \mathrm{m}(\bar{x}=53 \times 3.2 \mu \mathrm{m}, \mathrm{n}=20)$, overlapping fasciculate, fusiform, with tapering and rounded ends, straight to slightly curved, 11-13-septate, not constricted at septa, hyaline, smoothwalled. Asexual morph: hyphomycetous, helicosporous. Colonies on the MEA media superficial, effuse, gregarious, white to light pink. Mycelium composed of partly immersed, partly superficial, hyaline to pale brown, septate, abundantly branched hyphae, with masses of crowded, glistening conidia. Conidiophores micronematous, mononematous, flexuous, cylindrical, long, branched, septate, pale brown, smooth-walled. Conidiogenous cells 12-20 $\mu \mathrm{m}$ long, 1.5-2.5 $\mu \mathrm{m}$ wide, 


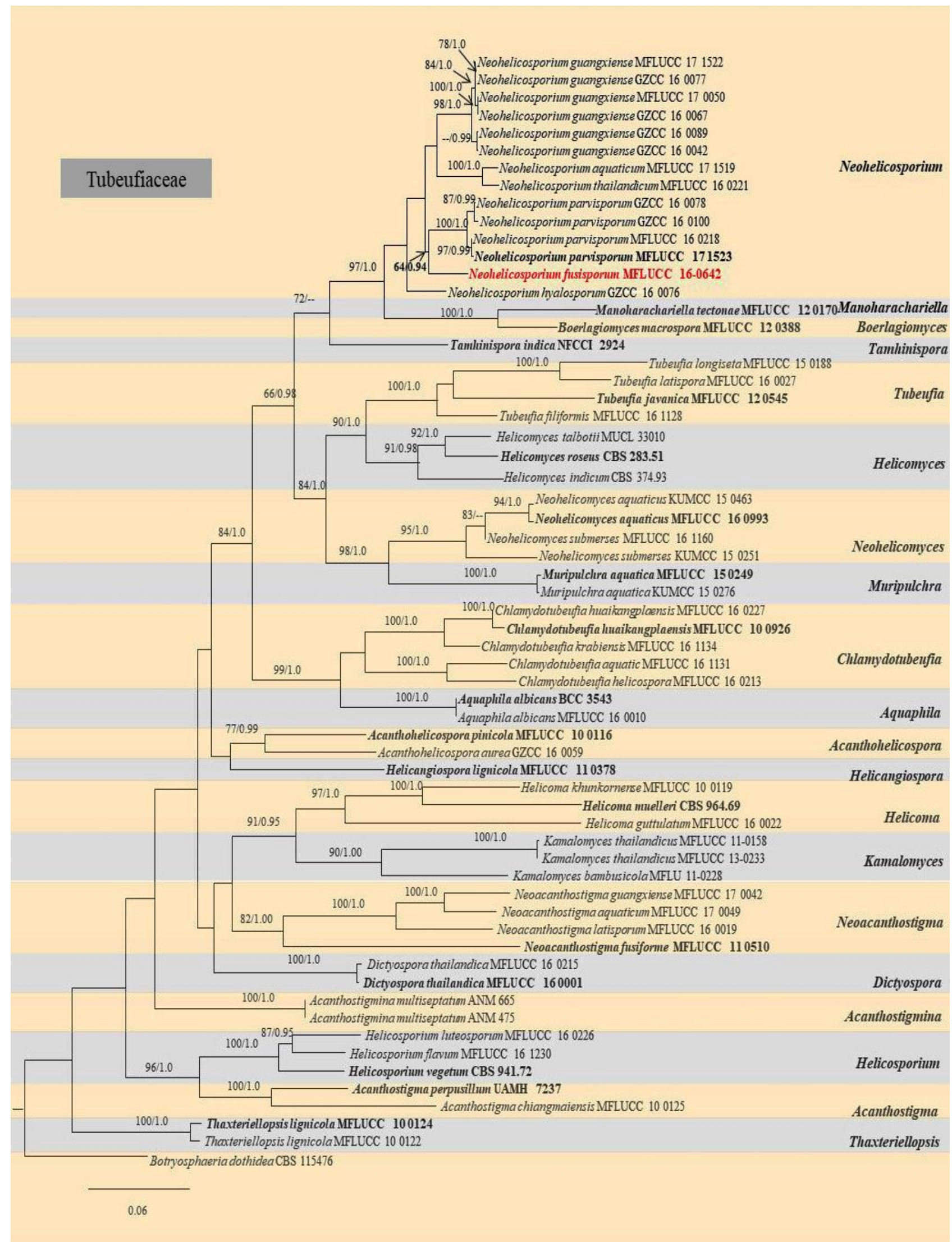

Fig. 1 - Simplified phylogram showing the best RAxML maximum likelihood tree obtained from the combined multigene (ITS, LSU and tefl) matrix of 62 taxa including genera in Tubeufiaceae. MLBS above $60 \%$ and Bayesian posterior probabilities above 0.90 are given at each branch. The tree is rooted with Botryosphaeria dothidea (CBS 115476) (Botryosphaeriaceae). The type species of each genus are in bold and the new fungal isolate is in bold red. 

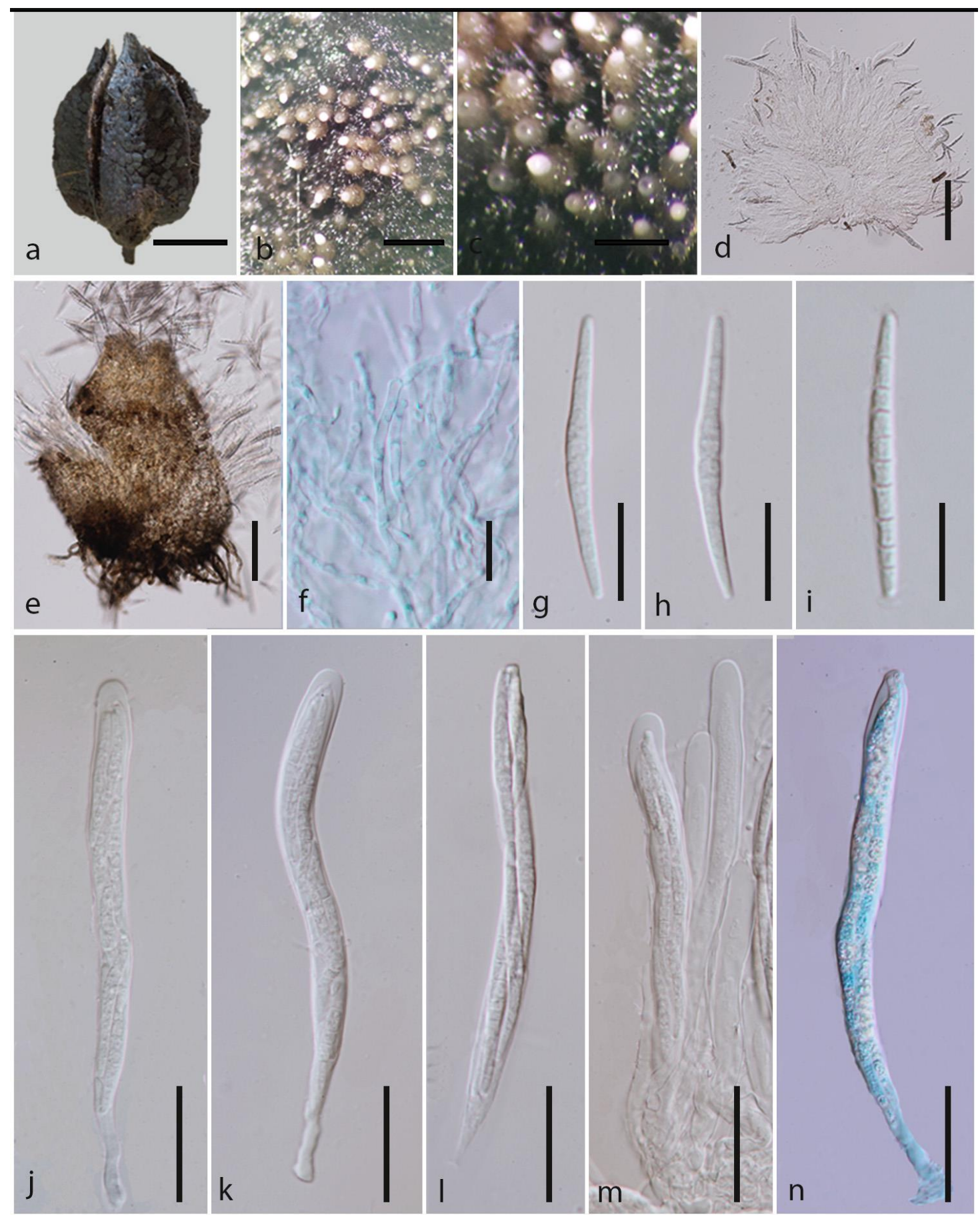

Fig. 2 - Neohelicosporium fusisporum (holotype). a The host fruit. b, c Superficial ascomata on substrate, white oozing mass of ascospores at apex of ascomata. $d$ White mass of ascomata. e View of ascoma with peridium cells. f Pseudoparaphyses. g-i Ascospores j-n Asci. Scale bars: $f=10 \mu \mathrm{m}$, $\mathrm{g}-\mathrm{i}=20 \mu \mathrm{m}, \mathrm{j}-\mathrm{n}=30 \mu \mathrm{m}$.

holoblastic, mono- to polyblastic, integrated, intercalary, cylindrical, with denticles, pale brown, smooth-walled. Conidia 18-22 $\mu \mathrm{m}$ diam. and conidial filament $1.5-2.5 \mu \mathrm{m}$ wide $(\bar{x}=18 \mu \mathrm{m} \times 2$ $\mu \mathrm{m}, \mathrm{n}=50$ ), $100-150 \mu \mathrm{m}$ long, tightly coiled $2 \frac{1}{2}-31 \frac{1}{4}$ times, loosely coiled in water, rounded at the ends, multi-septate, verrucose, guttulate, hyaline.

Colony morphology - Ascospores germinated on malt extract agar medium (MEA). On MEA colonies are appressed, circular, flat surface, edge entire, first cream then become dark brown and rise in the centre with mycelium, reverse brown reaching $10 \mathrm{~mm}$ in 2 weeks at $18{ }^{\circ} \mathrm{C}$. 
Material examined - Thailand, Krabi, Thanon Phet Kasem decaying fruit of Malvaceae sp. tree. Dec. 2015, Kevin D. Hyde, C 123 (MFLU 16-0950, holotype; PDD, isotype), ex-type living culture (MFUCC 16-0642, BCC). GenBank numbers - LSU: MG017613, ITS: MG017612, tef1: MG017614

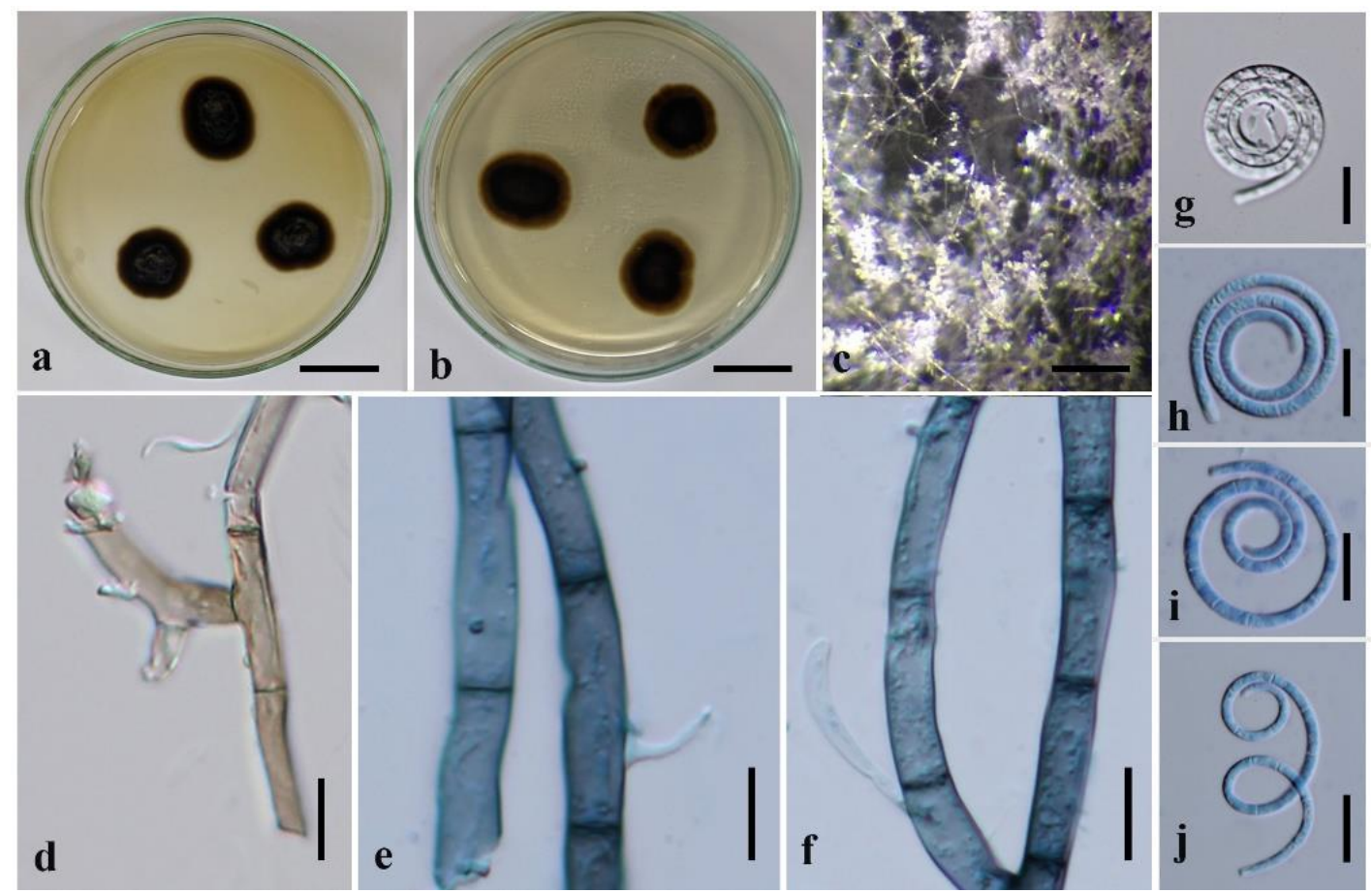

Fig. 3 - Neohelicosporium fusisporum asexual morph (from ex-type culture), a, b Upper and reverse view of the culture. c Appearance of fruiting bodies in culture. $d$-f Conidiophores with conidiogenous cells. g-j Conidia. Scale bars: $a, b=1 \mathrm{~cm}, \mathrm{c}=200 \mu \mathrm{m}, \mathrm{d}-\mathrm{j}=10 \mu \mathrm{m}$

\section{Discussion}

In this study, we introduce a new species in the genus Neohelicosporium based on morphological and multigene phylogenetic analyses. Neohelicosporium comprises five other species: $N$. aquaticum, $N$. guangxiense, $N$. hyalosporum, $N$. parvisporum (type species) and $N$. thailandicum. This genus was recently introduced as an asexual genus with helicoid conidia. Neohelicosporium is morphologically similar to Helicosporium species in conidial features but has distinct conidiophores. The conidiophores of $N$. parvisporum are flexuous, branched, hyphae-like, very long that makes measuring them difficult, while the conidiophores of Helicosporium species are erect, unbranched, fertile in the middle, sterile and tapering towards narrow subacute apex (Moore 1957, Goos 1989, Zhao et al. 2007, Boonmee et al. 2014).

Neohelicosporium fusisporum fits with the generic description of Neohelicosporium $(N$. parvisporum) (Lu et al. 2017d), however, it differs in having narrow conidiogenous cells (1.5-2.5 $\mu \mathrm{m}$ vs 3.5-4.5 $\mu \mathrm{m})$ and conidial filaments $(1.5-2.5 \mu \mathrm{m}$ vs $2-4 \mu \mathrm{m})$. Following the recommendations of Jeewon \& Hyde (2016) for delimitation of a new species, we noted eleven base pair differences between $N$. fusisporum and $N$. parvisporum in the ribosomal ITS sequences. In addition to six and 33 base pair differences in LSU and tefl sequences respectively. Therefore, we confirm $N$. fusisporum as a distinct new species within the genus Neohelicosporium.

The family Tubeufiaceae is known by both sexual and asexual genera, and some genera with both morphs. The sexual morph of $N$. fusisporum is reported from a decaying fruit and the asexual morph was found in a culture of the isolate. The sexual morph is similar to Tubeufia but differs in the morphology of the ascospores. Tubeufia species comprise elongate cylindric-subfusiform or narrowly oblong ascospores, however $N$. fusisporum is comprise fusiform ascospores. 


\section{Acknowledgment}

We are grateful to the Mushroom Research Foundation, Chiang Rai, Thailand for the financial support of the study.

\section{References}

Barr ME. 1980 - On the family Tubeufiaceae (Pleosporales). Mycotaxon 12, 137-167

Boonmee S, Rossman AY, Liu JK, Li WJ et al. 2014 - Tubeufiales, ord. nov., integrating sexual and asexual generic names. Fungal Diversity 68, 239-298

Boonmee S, Zhang Y, Chomnunti P, Chukeatirote E et al. 2011 - Revision of lignicolous Tubeufiaceae based on morphological reexamination and phylogenetic analysis. Fungal Diversity 51, 63-102

Brahamanage RS, Lu YZ, Bhat DJ, Wanasinghe DN et al. 2017 - Phylogenetic investigations on freshwater fungi in Tubeufiaceae (Tubeufiales) reveals the new genus Dictyospora and new species Chlamydotubeufia aquatica and Helicosporium flavum. Mycosphere 8, 917-933

Chaiwan N, Lu YZ, Tibpromma S, Bhat DJ et al. 2017 - Neotubeufia gen. nov. and Tubeufia guangxiensis sp. nov. (Tubeufiaceae) from freshwater habitats. Mycosphere 8, 1443-1456

Chomnunti P, Hongsanan S, Aguirre-Hudson B, Tian Q et al. 2014 - The sooty moulds. Fungal Diversity $66,1-36$

Darriba D, Taboada GL, Doallo R, Posada D. 2012 - jModelTest 2: more models, new heuristics and parallel computing. Nature Methods 9, 772.

Goos RD. 1989 - On the anamorph genera Helicosporium and Drepanospora. Mycologia 81, 356495

Guindon S, Gascuel O. 2003 - A simple, fast and accurate method to estimate large phylogenies by maximum-likelihood". Systematic Biology 52, 696-704.

Huelsenbeck JP, Ronquist F. 2001 - MRBAYES: Bayesian inference of phylogenetic trees. Bioinformatics 17, 754-755

Hyde KD, Hongsanan S, Jeewon R, Bhat DJ et al. 2016 - Fungal diversity notes 367-490: taxonomic and phylogenetic contributions to fungal taxa. Fungal Diversity 80, 1-270.

Hyde KD, McKenzie EHC, KoKo TW. 2011 - Towards incorporating anamorphic fungi in a natural classification-checklist and notes for 2010. Mycosphere 2, 1-88

Index Fungorum. 2017 - Available from: http://www.indexfungorum.org/Names/Names.asp. (accessed September 2017)

Jayasiri SC, Hyde KD, Ariyawansa HA, Bhat J et al. 2015 - The Faces of Fungi database: fungal names linked with morphology, phylogeny and human impacts. Fungal Diversity 74, 3-18.

Jeewon R, Hyde KD. 2016 - Establishing species boundaries and new taxa: recommendations to resolve 534 taxonomic ambiguities. Mycosphere 7, 1669-1677

Jeewon R, Ittoo J, Mahadeb D, Jaufeerally-Fakim Y et al. 2013 - DNA based identification and phylogenetic characterisation of endophytic and saprobic fungi from Antidesma madagascariense, a medicinal plant in Mauritius. Journal of Mycology 2013, 1-10

Kodsueb R, Jeewon R, Vijaykrishna D, Mckenzie EHC et al. 2006 - Systematic revision of Tubeufiaceae based on morphological and molecular data. Fungal Diversity 21, 105-130

Lu YZ, Boonmee S, Bhat DJ, Hyde KD et al. 2017c - Helicosporium luteosporum sp. nov. and Acanthohelicospora aurea (Tubeufiaceae, Tubeufiales) from terrestrial habitats. Phytotaxa 319, 241

Lu YZ, Boonmee S, Dai DQ, Liu JK et al. 2017a - Four new species of Tubeufia (Tubeufiaceae, Tubeufiales) from Thailand. Mycological Progress 16, 403-417

Lu YZ, Boonmee S, Liu JK, Hyde KD et al. 2017b - Novel Neoacanthostigma species from aquatic habitats. Cryptogamie, Mycologie 38, 169-190

Lu YZ, Boonmee S, Liu JK, Hyde KD et al. 2017d - Multi-gene phylogenetic analyses reveals Neohelicosporium gen. nov. and five new species of helicosporous hyphomycetes from aquatic habitats. Mycological progress (In prep) 
Luo ZL, Bhat DJ, Jeewon R, Boonmee S et al. 2017 - Molecular phylogeny and morphological characterization of asexual fungi (Tubeufiaceae) from freshwater habitats in Yunnan, China. Cryptogamie, Mycologie 38, 27-53

Miller MA, Pfeiffer W, Schwartz T. 2010 - Creating the CIPRES Science Gateway for inference of large phylogenetic trees. In Gateway Computing Environments Workshop 2010 (GCE), New Orleans, Louisiana, November 2010, pp 1-8

Moore RT. 1957 - Index to the Helicosporae: addenda. Mycologia 49, 580-587

Promputtha I, Miller AN. 2010 - Three new species of Acanthostigma (Tubeufiaceae, Dothideomycetes) from Great Smoky Mountains National Park. Mycologia 102, 574-587

Rambaut A, Drummond A. 2008 - FigTree: Tree figure drawing tool, version 1.2. 2. Institute of Evolutionary Biology, University of Edinburgh.

Rannala B, Yang Z. 1996 - Probability distribution of molecular evolutionary trees: a new method of phylogenetic inference. Journal of Molecular Evolution 43, 304-311

Rehner SA, Buckley E. 2005 - A Beauveria phylogeny inferred from nuclear ITS and EF1-alpha sequences: evidence for cryptic diversification and links to Cordyceps teleomorphs. Mycologia 97, 84-98

Rossman AY. 1987 - The Tubeufiaceae and similar Loculoascomycetes. Mycological Papers 157, $1-71$

Sánchez RM, Bianchinotti MV. 2010 - New records in the Tubeufiaceae from Andean Patagonian forests of Argentina. Mycotaxon 111, 131-141

Stamatakis A, Hoover P, Rougemont J. 2008 - A rapid bootstrap algorithm for the RAxML web servers. Systematic Biology 57, 758-771.

Tanney J, Miller AN. 2017 - Asexual-sexual morph connection in the type species of Berkleasmium. Biodiversity (Mycology and Botany), Eastern Cereal and Oilseed Research Centre, Agriculture and Agri-Food Canada, Ottawa, 99-105

Tsui CKM, Sivichai S, Berbee ML. 2006 - Molecular systematics of Helicoma, Helicomyces and Helicosporium and their teleomorphs inferred from rDNA sequences. Mycologia 98, 94-104

Tsui CKM, Sivichai S, Rossman AY, Berbee ML. 2007 - Tubeufia asiana, the teleomorph of Aquaphila albicans in the Tubeufiaceae, Pleosporales, based on cultural and molecular data. Mycologia 99, 884-894

Vilgalys R, Hester M. 1990 - Rapid genetic identification and mapping of enzymatically amplified ribosomal DNA from several Cryptococcus species. Journal of Bacteriology 172, 4238-4246

White TJ, Bruns T, Lee S, Taylor J. 1990 - Amplification and direct sequencing of fungal ribosomal RNA genes for phylogenetics. In: Innis MA, Gelfand DH, Sninsky JJ, White TJ (eds) PCR protocols: a guide to methods and applications. Academic, San Diego, pp 315-322

Zhao GZ, Liu X, Wu W. 2007 - Helicosporous hyphomycetes from China. Fungal Diversity, 26, $313-524$

Zhaxybayeva O, Gogarten JP. 2002 - Bootstrap, Bayesian probability and maximum likelihood mapping: exploring new tools for comparative genome analyses. BMC Genomics 3, 4. 